\title{
A new conjugated polymer with donor-acceptor architectures based on alternating 1,4-divinyl-2,5-dioctyloxybenzene and 5,8-(2,3-dipyridyl)-quinoxaline: Synthesis, characterization, and photoinduced charge transfer
}

\author{
S. J. Chen, Q. Y. Zhang", J. W. Gu, M. L. Ma, L. Zhang, J. Zhou, Y. Y. Zhou \\ Key Laboratory of Space Applied Physics and Chemistry, Ministry of Education, Department of Applied Chemistry, \\ Northwestern Polytechnical University, 710129 Shaanxi Xi'an, PR China
}

Received 25 October 2011; accepted in revised form 26 December 2011

\begin{abstract}
A new conjugated polymer with donor-accepter architectures poly[1,4-dioctyloxyphenylene-2,5-diylethenylene(2,3-dipyridine-2-ylquinoxaline-5,8-diyl)ethylene] (PPV-BD) was synthesized successfully, in which the electron-donating unit was alkoxy substituted phenyl ring, and the electron-accepting unit was a quinoxaline. The resulting polymer had a lower band-gap $(1.98 \mathrm{eV})$ compared to poly[2-methoxy-5-(2-ethyl)hexoxy-phenylenevinylene] (MEH-PPV, $2.12 \mathrm{eV})$, and was characterized by infrared spectroscopy (IR), nuclear magnetic resonance (NMR), thermogravimetric analysis (TGA), gel permeation chromatography (GPC), ultraviolet-visible (UV-vis) spectroscopy, photoluminescence (PL) spectroscopy and X-ray diffraction (XRD). Its photoinduced charge transfer applications in polymer solar cell (PSC) and trinitrotoluene (TNT) detection were studied respectively, and the results indicated that this polymer might be a good candidate material for PSC or detecting TNT in solution.
\end{abstract}

Keywords: polymer synthesis, characterization, chemosensor material, photoinduced charge transfer, photovoltaic material

\section{Introduction}

Conjugated polymers have attracted considerable attention due to their versatile applications in the fields of polymer light-emitting diodes (PLED) [13], polymer field-effect transistors (PFETs) [4, 5], chemical sensors [6], photodetectors [7], polymer solar cells (PSCs) [8], etc. In recent years, several polymers based on poly(phenylenevinylenes) (PPVs) have been synthesized and used as the active layer in photovoltaic devices [9-13]. A major drawback of most conjugated polymers for their application in PSCs is the rather poor match of the absorbance spectrum with the solar spectrum. The wavelength of maximum absorbance for most PPV derivatives lies below $500 \mathrm{~nm}\left(E_{\mathrm{g}}=2.0 \sim 2.2 \mathrm{eV}\right)$, which is on the far blue side of the spectrum $[14,15]$. By using low band-gap materials, an improved overlap with the solar spectrum would allow an increase in photovoltaic energy conversion. The band-gap of $\pi$-conjugated polymers can be controlled through the chemical structure of the system [16]. $\pi$-conjugated polymers with donor-acceptor architectures are currently of interest because the intramolecular charge transfer can facilitate ready manipulation of the electronic structure (HOMO/LUMO levels), leading to small band-gap semiconducting polymers [17-20]. In addition, conjugated polymers have been proven quite useful in creating highly sensi-

\footnotetext{
${ }^{*}$ Corresponding author, e-mail: qyzhang1803@gmail.com
} (c) BME-PT 
tive fluorescent chemical sensors [21-23]. The conjugated polymer backbone allows efficient electron delocalization and exciton migration over large distances, thereby creating amplified sensory responses compared with small-molecule-based sensors. An additional advantage of using polymers as sensor materials emerges from that the sensory devices can easily be fabricated from these materials on electrodes either by spin coating and/or drop casting from solution or anodic electrochemical polymerization from an electrolyte solution.

In this paper, a new conjugated polymer with donoraccepter architectures poly[1,4-dioctyloxyphenylene-2,5-diylethenylene-(2,3-dipyridine-2-ylquinoxaline-5,8-diyl)ethylene] (PPV-BD) was synthesized successfully, in which the electron-donating unit was alkoxy substituted phenyl rings, and the electron-accepting unit was a quinoxaline. The quinoxaline is a good electron-accepting unit, and it has been designed in donor-acceptor fluorine-based or thiophene-based copolymers [24]. The resulting polymer had a lower band-gap $(1.98 \mathrm{eV})$ compared to poly[2-methoxy-5-(2-ethyl)hexoxy-phenylenevinylene] (MEH-PPV, $2.12 \mathrm{eV}$ [25]), and was characterized by infrared spectroscopy (IR), nuclear magnetic resonance (NMR), thermogravimetric analysis (TGA), gel permeation chromatography (GPC), ultraviolet-visible (UV-vis) and photoluminescence (PL) spectroscopy. Additionally, its photoinduced charge transfer (PCT) applications in PSCs and trinitrotoluene (TNT) detection were studied respectively, and the results indicated that this polymer might be a good candidate material for PSCs or detecting TNT in solution. The molecular structure of PPV-BD is shown in Figure 1.

\section{Experimental}

\subsection{Materials}

The main reagents such as p-hydroquinone (AR, Analytical Reagent), palladium (II) acetate (AR), 2,2'-bipyridyl (AR), [Bu(4)N]BF(4) (AR) were purchased from J\&K Scientific Ltd., China, used as received. All the solvents used in this study were purified according to standard methods prior to use.

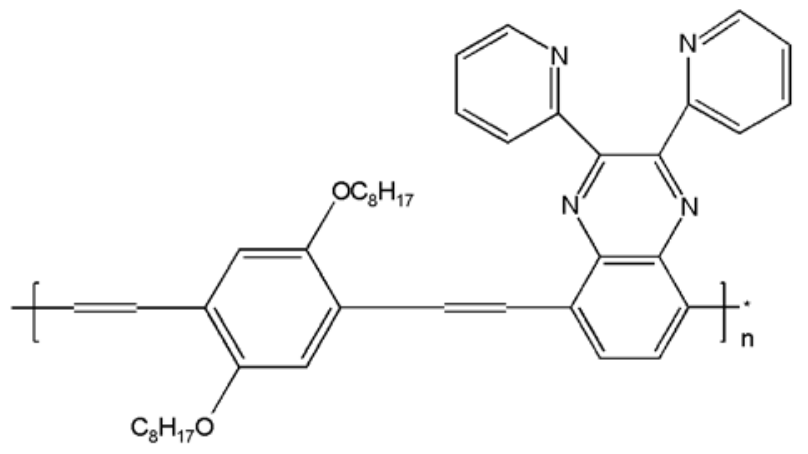

PPV-BD

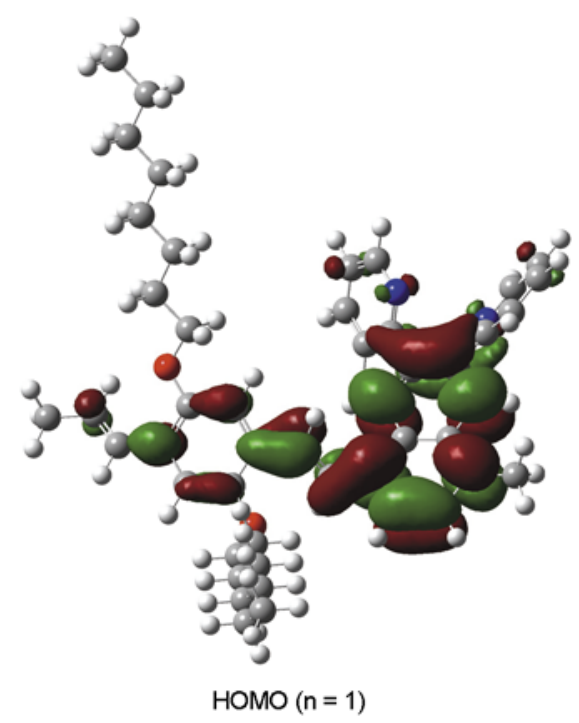

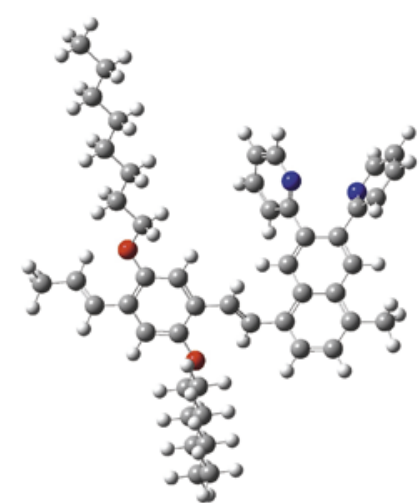

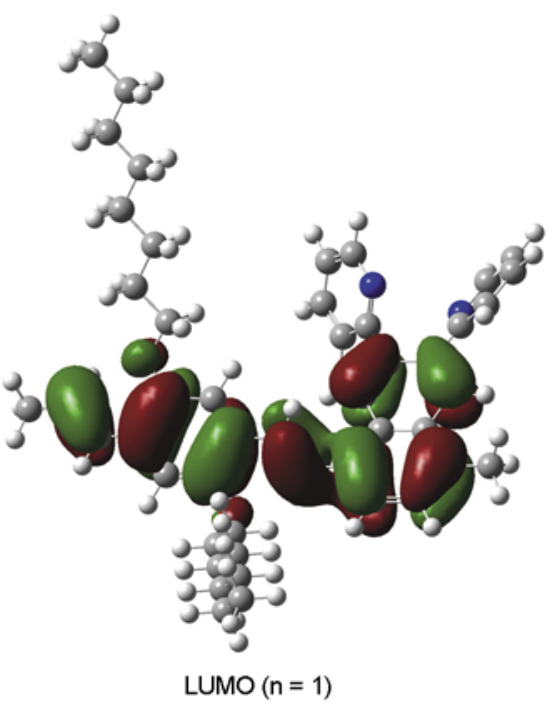

Figure 1. Molecular structure of polymer PPV-BD 
1,4-divinyl-2,5-dioctyloxybenzene (monomers 1) and 5,8-dibromo-2,3-dipyridylquinoxaline (monomer 2) were synthesized according to the published literatures [26-28].

\subsection{Measurements}

The target compounds were characterized by NMR spectra using Bruker AVANCE 400 spectrometer (Bruker Corporation, Karlsruhe, Germany) with chloroform-d as the solvent and tetramethylsilane as the internal standard. Polymer molecular weight was determined by size-exclusion chromatography with multi-angle laser light-scattering detection (SEC-MALLS). SEC was performed using a highperformance liquid chromatography (HPLC) pump (Waters 515, Waters Corporation, USA) and a column $(200 \mathrm{~mm} \times 0.8 \mathrm{~mm}$, MZ-Gel SDplus $500 \AA$ $5 \mu \mathrm{m})$. Column effluent was monitored sequentially with a miniDawn light-scattering detector (Wyatt technology Corporation, Santa, Barbara, CA, USA) and an Optical rEX differential refractometer (Wyatt Technology Corporation, Santa, Barbara, CA, USA). Two $25 \mathrm{~mm}$ high-pressure filter with 0.22 and $0.1 \mu \mathrm{m}$ pores (Millipore Corporation, Bedford, Massachusetts, USA) were used for on-line filtration of the mobile phase. UV-vis spectra were recorded on a Shimadzu UV-2501PC/2550 (Shimadzu Corporation, Kyoto, Japan). Photoluminescence spectra were measured in a HITACHI F-4600 fluorescence spectrometer (Hitachi Corporation, Tokyo, Japan). FTIR spectra were taken on a Bruker Tensor 27FT-IR spectrophotometer (Bruker Corporation, Karlsruhe, Germany) with $\mathrm{KBr}$ pellets. Thermogravimetric analysis (TGA) of the synthesized polymer was performed on a HENVEN HCT-1 (Beijing Scientific Instrument Factory, Beijing, China) thermal analysis system at a heating rate of $10^{\circ} \mathrm{C} / \mathrm{min}$ up to $500^{\circ} \mathrm{C}$ in a nitrogen flow rate of $80 \mathrm{~mL} / \mathrm{min}$. Ele-

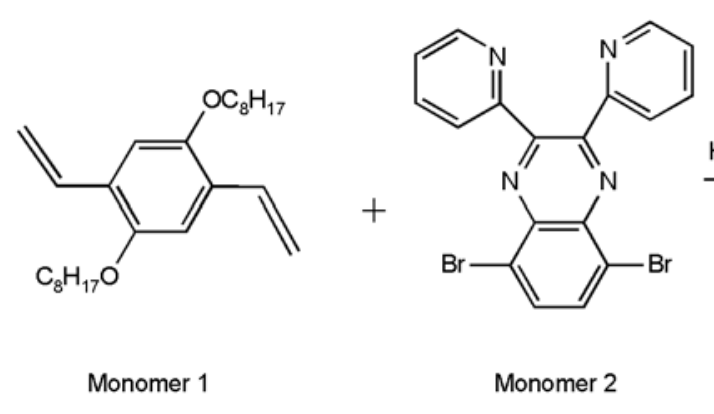

mental C, H, N was performed on a Flash EA 1112 elemental analyzer (Thermo Electron Corporation, Waltham, USA). Cyclic voltammetry was carried out using thin films of polymer prepared from chloroform with PARSTAT-2273 (Princeton Applied Research, AMETEK, Inc., Oak Ridge, USA) in a solution of $[\mathrm{Bu}(4) \mathrm{N}] \mathrm{BF}(4)(0.1 \mathrm{M})$ in acetonitrile at a scan rate $50 \mathrm{mV} / \mathrm{s}$. Scanning electron microscope (SEM) images were performed in Shimadzu SSX550 (Shimadzu Corporation, Kyoto, Japan). X-ray diffraction (XRD) data were collected using a Siemens Bruker D500 X-ray diffractometer (Bruker Corporation, Karlsruhe, Germany) at a scanning rate of $4 \% \mathrm{~min}$ in the $2 \theta$ range from 0 to $80^{\circ}$, with graphite monochromatized $\mathrm{Cu} \mathrm{K} \alpha$ radiation.

\subsection{Syntheses of monomers and polymer}

PPV-BD was synthesized via the Heck reaction polycondensation between monomer 1 and monomer 2 in presence of palladium (II) acetate catalyst. The synthetic routes of polymer PPV-BD are shown in Figure 2.

The syntheses of the monomer 1, monomer 2 and polymer PPV-BD are described as follows:

\section{Synthesis of monomer 1 [26, 27]}

Monomer 1 was synthesized according to the literatures [26, 27]. $18.06 \mathrm{~g}(17.3 \mathrm{mmol})$ of 1,4-bis(bromide-triphenylphosphine methyl)-2,5-dioctyloxybenzene was dissolved in a co-solvent of $230 \mathrm{~mL}$ dichloromethane and $70 \mathrm{~mL}(40 \%)$ formaldehyde solution. Then, $140 \mathrm{~mL}(20 \%) \mathrm{NaOH}$ solution was added dropwise, the mixture was stirred for $15 \mathrm{~h}$ at $0^{\circ} \mathrm{C}$ under inert atmosphere. Finally, $30 \mathrm{~mL}$ water and $60 \mathrm{~mL}$ dichloromethane were added into the reactive solution. The organic layer was separated and washed by water, then dried with anhydrous $\mathrm{Na}_{2} \mathrm{SO}_{4}$. The crude product was formed after sol-

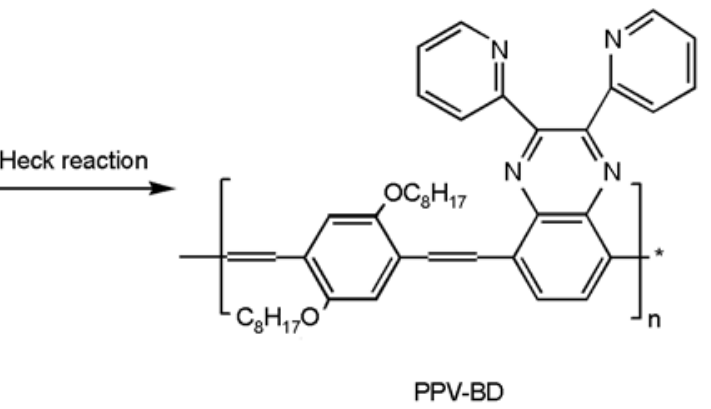

Figure 2. Synthetic routes of polymer PPV-BD 


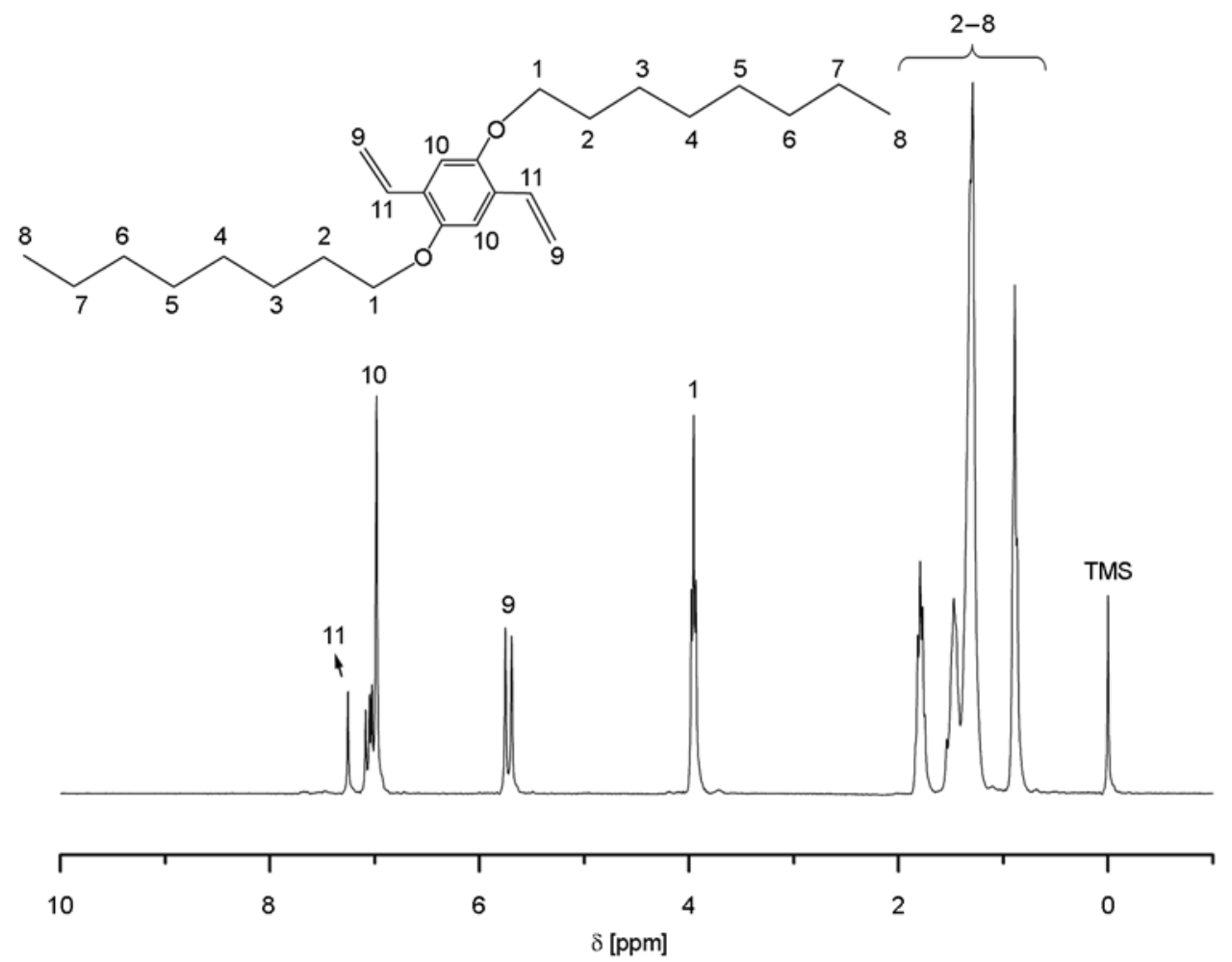

Figure 3. ${ }^{1} \mathrm{H}$ NMR spectrum of 1,4-bis(octyloxy)-2,5-divinylbenzene

vents evaporating, and recrystallized with ethanol several times to get $3.68 \mathrm{~g}$ of monomer 1 as white crystals. Yield 55\%, mp: $45-46^{\circ} \mathrm{C}$.

${ }^{1} \mathrm{H}$ NMR $\left(\mathrm{CDCl}_{3} ; \delta / \mathrm{ppm}\right): 0.87-1.82$ (m, 30H, H2$\mathrm{H} 8), 3.93-3.98$ (t, 4H, H1), 5.69-5.71 (d, 4H, H9), 6.98 (s, 2H, H10), 7.03-7.08 (t, 2H, H11) (details in Figure 3). FT-IR $\left(\mathrm{KBr}, \mathrm{cm}^{-1}\right): 3082(\mathrm{v}(\mathrm{Ar}-\mathrm{H})$, $\left.v\left(=\mathrm{CH}_{2}\right)\right), 3019(v(=\mathrm{CH})), 2943,2919\left(v_{\text {as }}\left(-\mathrm{CH}_{3}\right.\right.$, $\left.\left.-\mathrm{CH}_{2}-\right)\right), 2850\left(v_{\mathrm{s}}\left(-\mathrm{CH}_{3},-\mathrm{CH}_{2}-\right)\right), 1212(\mathrm{v}(\mathrm{C}-\mathrm{O})$, 1618, 1500, $1466(\operatorname{Ar}(\mathrm{C}=\mathrm{C})$, vinyl-v $(\mathrm{C}=\mathrm{C})), 993$, $893\left(\gamma\left(\mathrm{CH}=\mathrm{CH}_{2}\right)\right)$. Anal. Calcd. $(\%)$ for $\mathrm{C}_{26} \mathrm{H}_{42} \mathrm{O}_{2}$ (386.61): C, 80.77; H, 10.95. Found (\%): C, 80.71; $\mathrm{H}, 12.27$.

Synthesis of monomer 2 [28]

A solution of 2,3-diamino-1,4-dibromobenzene $(1.03 \mathrm{~g}, 3.8 \mathrm{mmol})$ and 2,2'-bipyridil $(0.806 \mathrm{~g}$, $3.8 \mathrm{mmol}$ ) in $25 \mathrm{~mL}$ ethanol was heated to reflux for $3 \mathrm{~h}$, then cooled to $0^{\circ} \mathrm{C}$. The formed precipitate was isolated by filtration and washed with ethanol to afford $1.16 \mathrm{~g}$ of monomer 2 as yellow solid. Yield $70 \%$, mp: $251-253^{\circ} \mathrm{C}$.

${ }^{1} \mathrm{H}$ NMR $\left(\mathrm{CDCl}_{3} ; \delta / \mathrm{ppm}\right): 7.25-7.28(\mathrm{~d}, 2 \mathrm{H}, \mathrm{H} 4)$, 7.87-7.98 (d, 2H, H1, H2, H3), 8.26-8.32 (m, 4H, $\mathrm{H} 5)$ (details in Figure 4). ${ }^{13} \mathrm{C} \mathrm{NMR}\left(\mathrm{CDCl}_{3} ; \delta / \mathrm{ppm}\right)$ : 123.4, 123.8, 124.5, 133.6, 136.9, 139.3, 148.2,

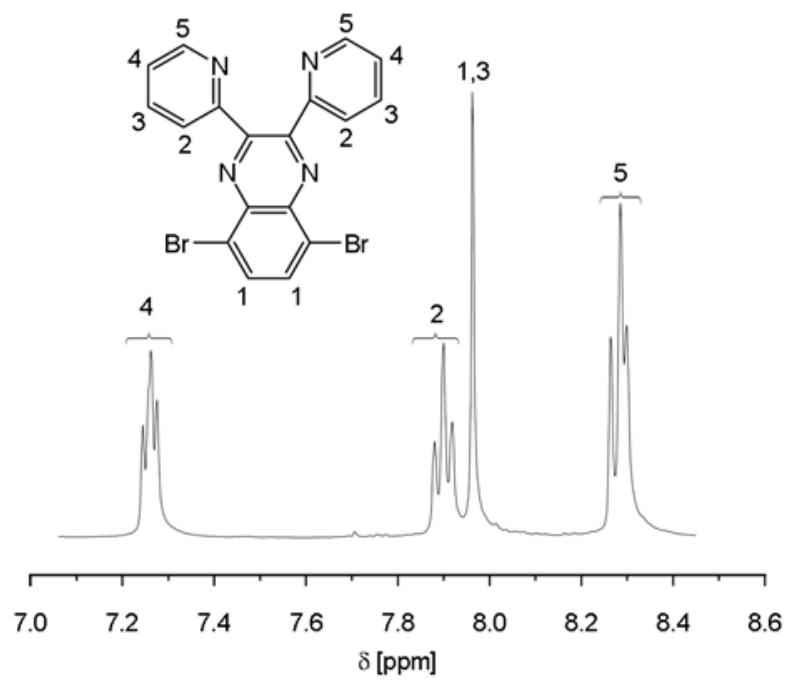

Figure 4. ${ }^{1} \mathrm{H}$ NMR spectrum of 5,8-dibromo-2, 3-dipyridyquinoxaline

153.4, 156.5. Anal. Calcd. (\%) for $\mathrm{C}_{18} \mathrm{H}_{10} \mathrm{Br}_{2} \mathrm{~N}_{4}$ (442.11): C, 48.90; H, 2.28; N, 12.67. Found (\%): C, 48.01; H, 2.47; N, 11.53.

\section{Synthesis of PPV-BD}

$250 \mathrm{mg}(0.65 \mathrm{mmol})$ of monomer $1,240 \mathrm{mg}$ ( $0.65 \mathrm{mmol})$ of monomer $2,14.6 \mathrm{mg}(0.065 \mathrm{mmol})$ of palladium acetate and $248 \mathrm{mg}(0.81 \mathrm{mmol})$ of tris(2-methylphenyl)phosphine were added into a 


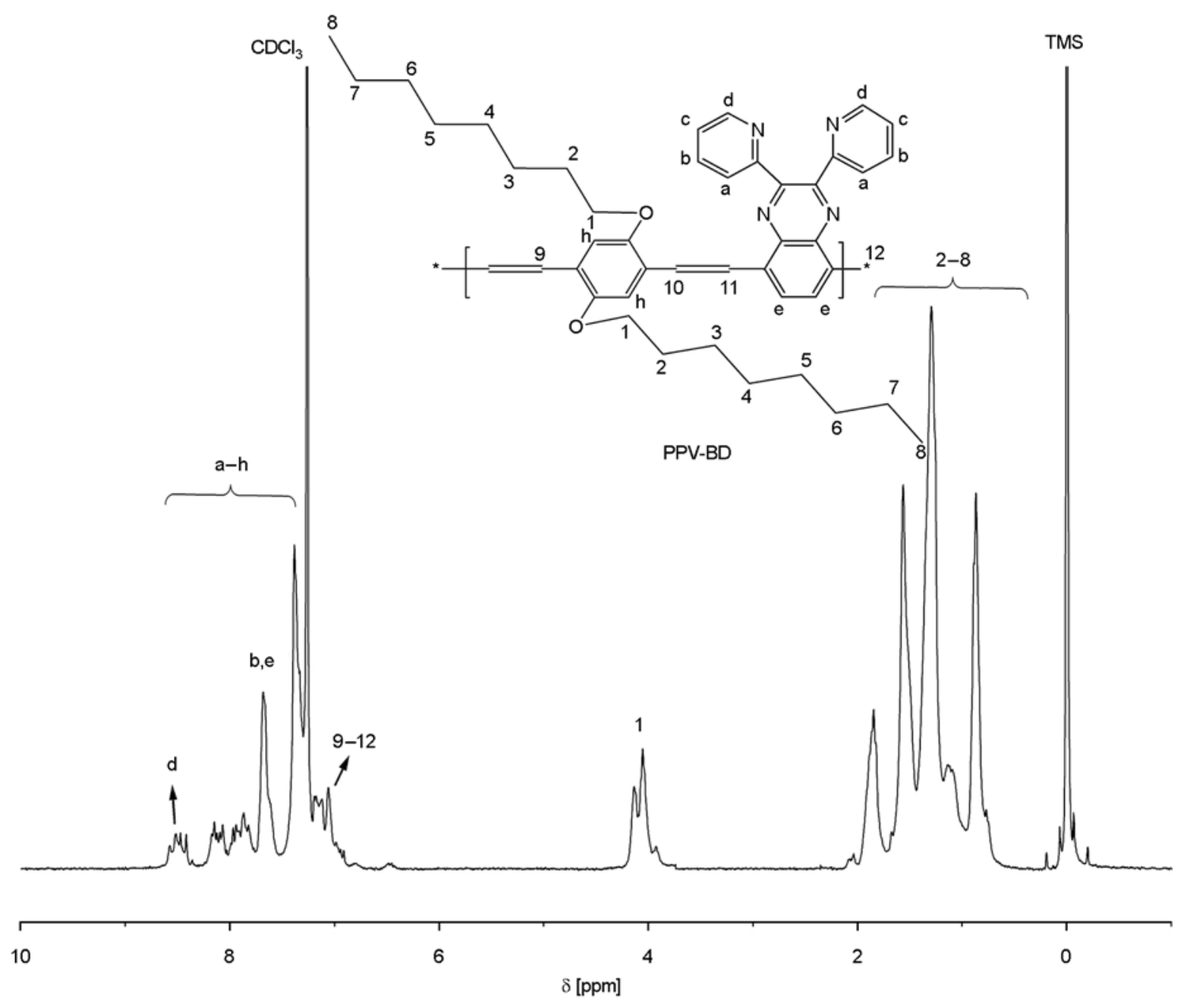

Figure 5. ${ }^{1} \mathrm{H}$ NMR spectrum in $\mathrm{CDCl}_{3}$ of $\mathrm{PPV}-\mathrm{BD}$

co-solvent of $4 \mathrm{~mL}$ triethylamine and $10 \mathrm{~mL} \mathrm{~N}^{\prime} \mathrm{N}-$ dimethylformamide. The mixed solution was heated to reflux for $24 \mathrm{~h}$ under inert atmosphere. After cooling to room temperature, the reactant was added into $300 \mathrm{~mL}$ methanol slowly. The resulting precipitate was centrifugated to collect $150 \mathrm{mg}$ of polymer PPV-BD as a deep-red powder. Yield $36 \%$.

${ }^{1} \mathrm{H}$ NMR $\left(\mathrm{CDCl}_{3}\right.$; $\left.\delta / \mathrm{ppm}\right)$ : 0.77-1.85 (m, 30H, H2H8), 3.93-4.14 (d, 4H, H1), 6.98-7.19 (m, 4H, H9$\mathrm{H} 12), 7.33-8.52$ (m, 12H, Ha-Hh) (details in Figure 5). FT-IR( $\left.\mathrm{KBr}, \mathrm{cm}^{-1}\right): 3060$ (v (Ar-H, or vinyl$\mathrm{H})), 2930\left(v_{\text {as }}\left(-\mathrm{CH}_{3},-\mathrm{CH}_{2}-\right)\right), 2850\left(v_{\mathrm{s}}\left(-\mathrm{CH}_{3}\right.\right.$, $\left.\left.-\mathrm{CH}_{2}-\right)\right), 1672(v(\mathrm{C}=\mathrm{N})), 1595,1466(v(\mathrm{Ar}(\mathrm{C}=\mathrm{C}))$,

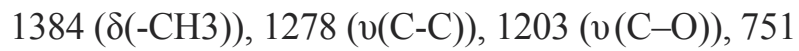
$\left(\gamma(\operatorname{Ar}(=\mathrm{CH}))\right.$. GPC (polystyrene standards): $M_{\mathrm{n}}=$ $11010, M_{\mathrm{w}}=15$ 050, PDI = 1.37. Anal. Calcd. $(\%)$ for $\left(\mathrm{C}_{44} \mathrm{H}_{50} \mathrm{~N}_{4} \mathrm{O}_{2}\right)_{\mathrm{n}}(666.92)_{\mathrm{n}}$ : C, 79.05; H, 7.78; N, 8.38. Found (\%): C, 80.74; H, 6.88; N, 7.48.

\section{Results and discussion}

\subsection{Solubility and thermal stability}

Since introducing the flexible long-chain alkyl into the benzene ring, polymer PPV-BD has a good solubility in polar solvents such as chloroform, tetrahy-

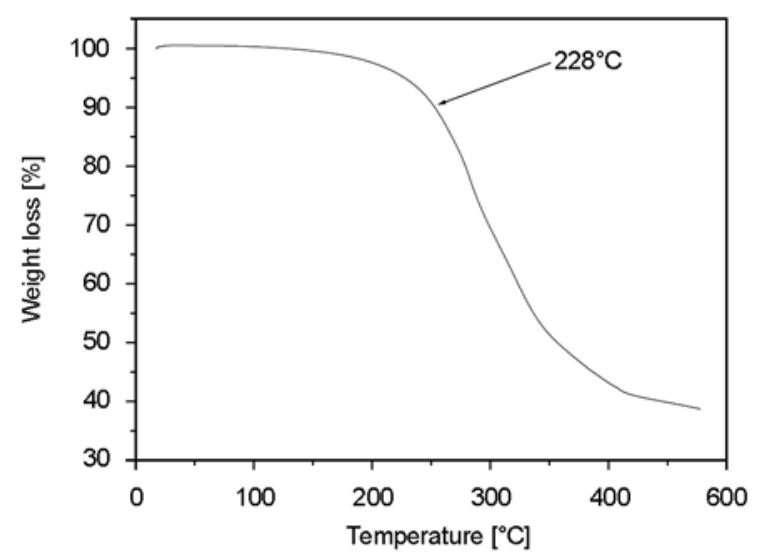

Figure 6. TGA curve of PPV-BD 
drofuran and 1,2-dichlorobenzene, and the maximum solubility in chloroform is about $27 \mathrm{mg} / \mathrm{mL}$. Figure 6 shows the TGA traces of polymer PPVBD. The polymer showed almost no mass loss at a low temperature, but exhibited a weight loss of approximately $5 \%$ at $228^{\circ} \mathrm{C}$. Hence, it can be concluded that the polymer PPV-BD has good thermal stability in a nitrogen atmosphere, which is suitable for application in optoelectronic devices.

\subsection{Absorption and fluorescence properties}

In order to investigate the relationships between the thickness and fluorescent performance, different thickness of polymer films were chosen to test their fluorescence properties by photoluminescence spectroscopy. The different thickness of polymer films were prepared by dissolving a certain mass of PPV$\mathrm{BD}$ in chloroform to get different concentration samples (a: $5 \mathrm{mg} / \mathrm{mL}$, b: $10 \mathrm{mg} / \mathrm{mL}$, c: $15 \mathrm{mg} / \mathrm{mL}$, d: $20 \mathrm{mg} / \mathrm{mL}$, e: $27 \mathrm{mg} / \mathrm{mL}$ ). Different thickness of polymer thin-films were deposited on quartz with a KW-4A spin coater (Institute of Microelectronics of Chinese Academy of Science, China) at a spin rate of $800 \mathrm{rpm}$ using the above solutions, and placed under vacuum overnight before test. Figure 7 is the PL emission spectra of different thickness of PPVBD films. It can be seen from the Figure 7, with the concentration of PPV-BD increasing, the maximum PL wavelength is red-shifting gradually. The maximum PL wavelength of PPV-BD film $(625 \mathrm{~nm})$ pre-

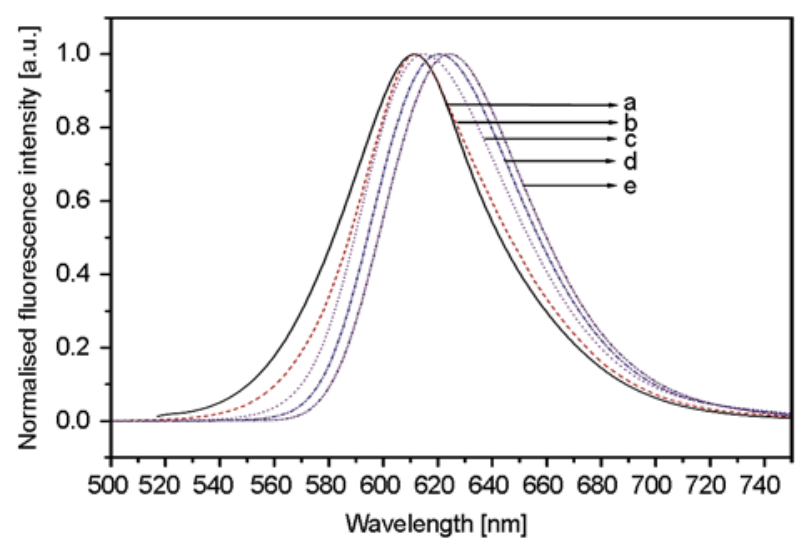

Figure 7. PL emission spectra of different thickness of PPVBD films (a: $5 \mathrm{mg} / \mathrm{mL}$, b: $10 \mathrm{mg} / \mathrm{mL}$, c: $15 \mathrm{mg} / \mathrm{mL}$, d: $20 \mathrm{mg} / \mathrm{mL}$, e: $27 \mathrm{mg} / \mathrm{mL}$ )

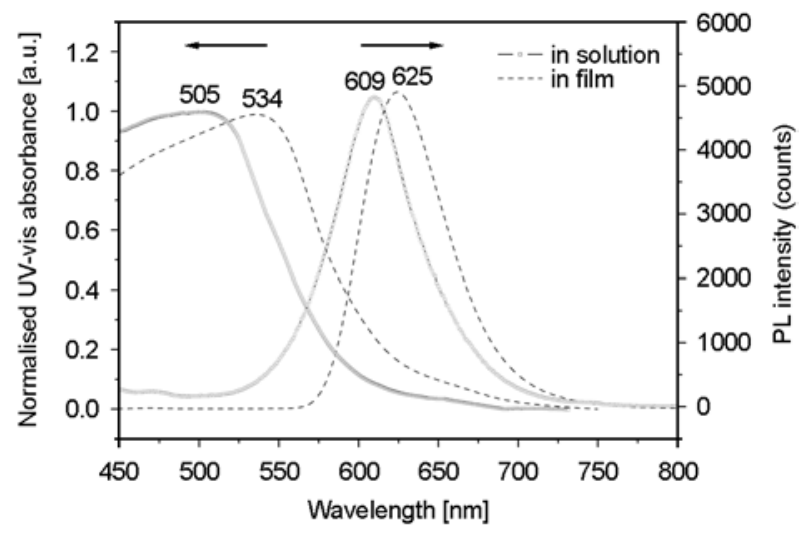

Figure 8. UV-vis spectra and PL-emission spectra (Ex: $350 \mathrm{~nm}$ ) of PPV-BD in $\mathrm{CHCl}_{3}$ and in film

pared from the maximum concentration $(27 \mathrm{mg} / \mathrm{mL})$ shows the largest red-shifting which red shift about $10 \mathrm{~nm}$ compared to that of PPV-BD film $(615 \mathrm{~nm})$ prepared from minimum concentration $(5 \mathrm{mg} / \mathrm{mL})$. Perhaps, with the solution concentration increasing, the thickness of film is increased accordingly, the thicker film will lead to a better $\pi-\pi^{*}$ stacking, therefore, presenting a larger red-shifting.

The photophysical characteristic of PPV-BD was investigated by UV-vis spectroscopy and photoluminescence spectroscopy in dilute chloroform solution $(0.035 \mathrm{mg} / \mathrm{mL})$ and in film (prepared from $27 \mathrm{mg} / \mathrm{mL}$ solution) on quartz, respectively. The UV-vis absorption spectra and photoluminescence emission spectra of polymer PPV-BD in $\mathrm{CHCl}_{3}$ and film are shown in Figure 8. Optical data of the polymer PPV$\mathrm{BD}$ and MEH-PPV are summarized in Table 1. Figure 9 shows the molecular structure of MEH-PPV.

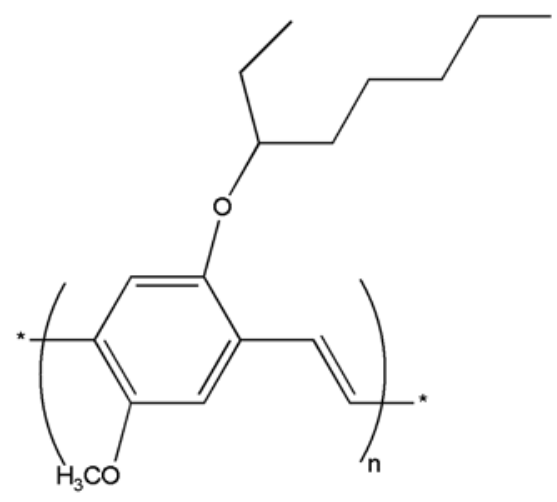

Figure 9. Molecular structure of MEH-PPV

Table 1. Optical data of polymers PPV-BD and MEH-PPV

\begin{tabular}{|l|c|c|c|c|c|c|c|c|}
\hline \multirow{2}{*}{ Polymer } & \multicolumn{4}{c|}{ UV-vis [nm] } & \multicolumn{2}{c|}{ PL-em [nm] } & \multicolumn{2}{c|}{$\mathbf{E}_{\mathbf{g}}{ }^{\text {opt }}[\mathbf{e V}]$} \\
\cline { 2 - 11 } & $\lambda_{\max }\left(\mathbf{C H C l}_{\mathbf{3}}\right)$ & $\lambda_{\max }(\mathbf{f i l m})$ & $\boldsymbol{\lambda}_{\text {onset }}\left(\mathbf{C H C l}_{\mathbf{3}}\right)$ & $\boldsymbol{\lambda}_{\text {onset }}(\mathbf{f i l m})$ & $\boldsymbol{\lambda}_{\max }\left(\mathbf{C H C l}_{\mathbf{3}}\right)$ & $\boldsymbol{\lambda}_{\max }$ (film) & $\mathbf{C H C l}_{\mathbf{3}}$ & film \\
\hline PPV-BD & 505 & 534 & 609 & 625 & 609 & 625 & 2.03 & 1.98 \\
\hline MEH-PPV[25] & 490 & 503 & 565 & 590 & - & - & 2.20 & 2.12 \\
\hline
\end{tabular}


It can be seen from Figure 8 that polymer PPV-BD presents a slight red-shifting in their principal absorption and fluorescence bands in thin films relative to in solution. It may be attribute to conformational preferences in thin films that the interpolymer interactions is increased, forming a $\pi$-stacking of polymer chains $[29,30]$.

Table 1 shows the maxima of absorption at long wavelength of polymers PPV-BD and MEH-PPV in chloroform at 505 and $490 \mathrm{~nm}$ respectively, and 534 and $503 \mathrm{~nm}$ in film respectively. The results show that the absorption maximum of PPV-BD exhibits a $29 \mathrm{~nm}$ red-shifting in $\mathrm{CHCl}_{3}$ and $31 \mathrm{~nm}$ red-shifting in film compared to MEH-PPV, respectively. Furthermore, the absorption spectrum onset of PPV$\mathrm{BD}$ in chloroform is at about $609 \mathrm{~nm}$, shifting to a longer wavelength compared to MEH-PPV $\left(\lambda_{\text {onset }}=\right.$ $565 \mathrm{~nm}, E_{\mathrm{g}}{ }^{\text {opt }}=2.20 \mathrm{eV}$ ), corresponding to an optical band-gap $\left(E_{\mathrm{g}}{ }^{\mathrm{opt}}\right)$ of $2.03 \mathrm{eV}$. As anticipated, the alternation of electron-rich alkoxy substituted aromatic and electron-deficient quinoxaline units along conjugated backbone results in a decrease of the band-gap. The results show that PPV copolymers containing electron-acceptor unit quinoxaline can lower the band-gap.

As described above, the red-shifting of the UV-vis peak in film (Figure 8) suggests that PPV-BD assumes a self-assembled stacked structure in the solid state [31]. The XRD pattern of PPV-BD shown in Figure 10 supports this view. According to the Bragg equation (Equation (1)):

$2 d \sin \theta=n \lambda$

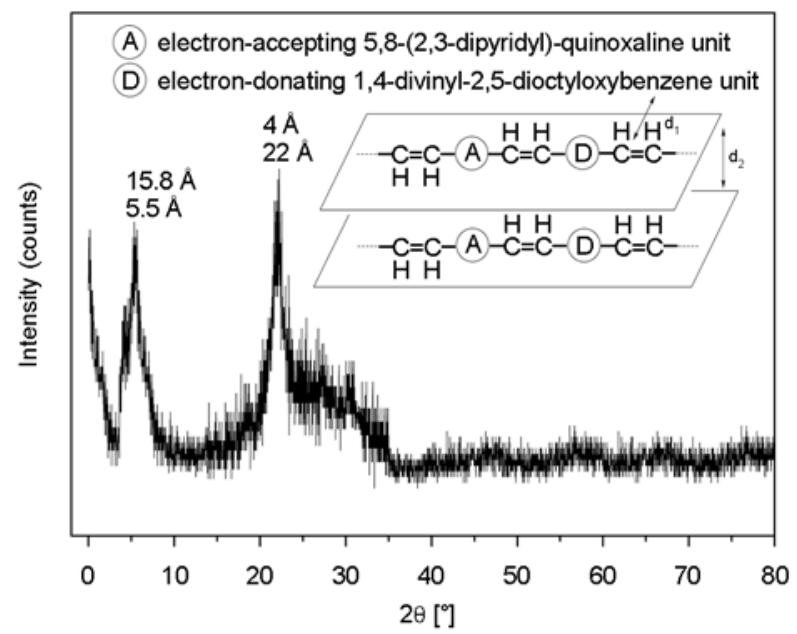

Figure 10. XRD pattern of PPV-BD. The inset is a diagrammatic drawing of PPV-BD film
The peak with a $d$ value of $15.8 \AA$ is considered to correspond to the distance between the main chains separated by the octyloxy group $\left(d_{1}\right)$; the peak with a $d$ value of $4.0 \AA$ is considered to correspond to the face-to-face distance between coplanar polymer chains $\left(d_{2}\right)$.

\subsection{Potoinduced Charge Transfer studies}

\subsubsection{PCT in polymer solar cell}

Polymer PPV-BD and fullerene $\mathrm{C}_{60}$ (PPV-BD/ $\mathrm{C}_{60}$ $\sim$ approximately $1 / 4, \mathrm{w} / \mathrm{w}$ ) were dissolved in 1,2 dichlorobenzene. Polymer thin films were deposited on quartz with a KW-4A spin coater at a spin rate of $1000 \mathrm{rpm}$ by using the above solution. The PLemission spectra are shown in Figure 11. It shows that when the polymer PPV-BD is blended with fullerene $\mathrm{C}_{60}$, the fluorescence of PPV-BD almost completely quenched. According to the quenching rate formula (Equation (2)):

$$
Q \%=\frac{f_{\mathrm{a}}-f_{\mathrm{b}}}{f_{\mathrm{a}}} \cdot 100
$$

where, $Q \%$ denotes quenching rate, $f_{\mathrm{a}}$ denotes fluorescence intensity when the quencher mass is zero, $f_{\mathrm{b}}$ denotes the fluorescence intensity when a certain mass of quencher is added to the polymer. Thus, we can get the final fluorescence quenching rate of PPV$\mathrm{BD}$ is $99.8 \%\left(\mathrm{PPV}-\mathrm{BD} / \mathrm{C}_{60} \sim 1 / 4, \mathrm{w} / \mathrm{w}\right)$. Because energy (exciton) transfer from the polymer to $\mathrm{C}_{60}$ is highly endergonic. We attribute the fluorescence quenching to electron transfer, although a contribution from increased nonradiative decay (e.g., intersysterm crossing) cannot be ruled out. From these results, it can be referred that the polymer PPV-BD may be a good candidate photovoltaic material for PSCs.

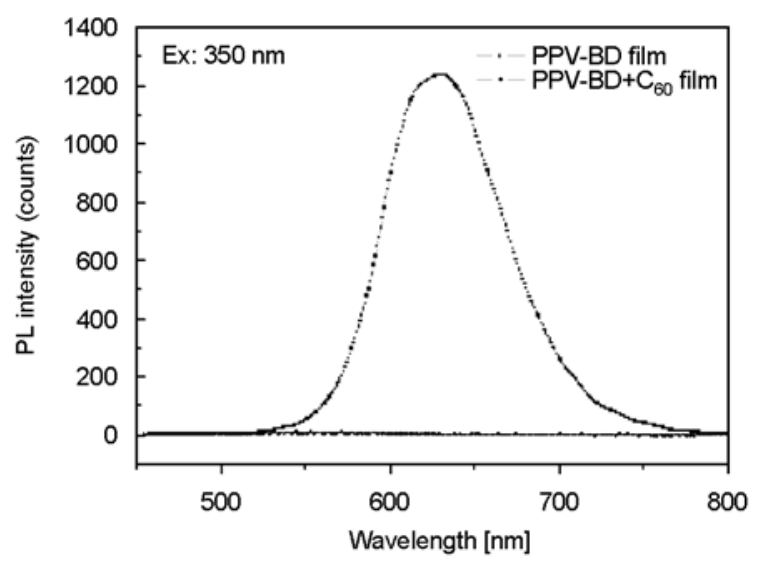

Figure 11. PL-emission spectra of PPV-BD and PPV-BD/ $\mathrm{C}_{60}$ (approximately $1 / 4, \mathrm{w} / \mathrm{w}$ ) in films 


\subsubsection{PCT application in TNT Detection}

A mixed solution was prepared by dissolving $1.4 \mathrm{mg}$ PPV-BD in $14 \mathrm{~mL}$ chloroform, then dividing it into seven parts to get samples $(0.1 \mathrm{mg} / \mathrm{mL})$. Each part of the PPV-BD solution was mixed with a chloroform solution of TNT $(0,5,50,300,500,1000$, $4000 \mathrm{ppm})$, respectively. The fluorescent properties of the mixtures were recorded immediately by fluorescence spectra at excitation wavelengths of $350 \mathrm{~nm}$.

Figure 12 shows the PL-emission spectra of PPV-BD in chloroform solution upon successively adding different concentrations of TNT solution. The intensity of the fluorescence decreased gradually as the concentration of TNT increased, which may be attributed to the destruction of the polymer conjugation upon interacting with TNT molecules. As we know, one property of nitroaromatics which may be exploited in detection schemes is the electron accepting capability. Substitution of the electron-withdrawing nitro groups on the aromatic ring lowers

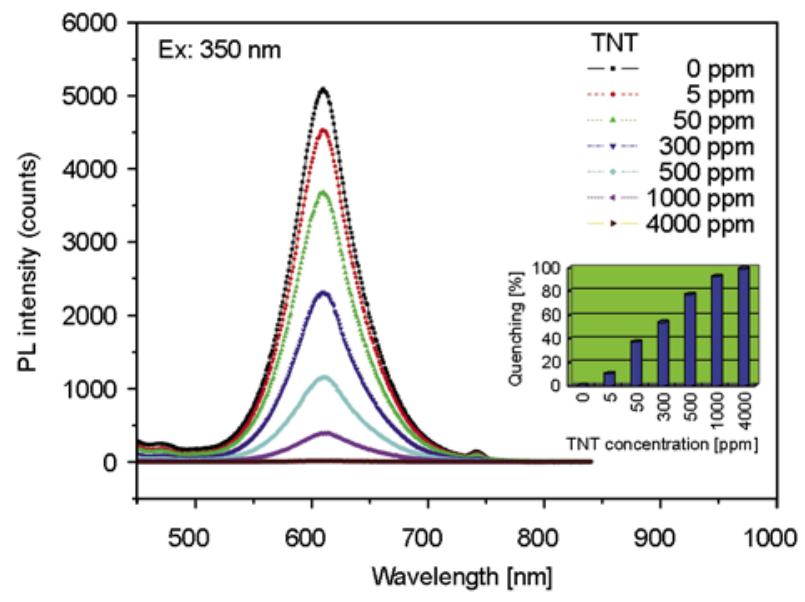

Figure 12. PL-emission spectra of PPV-BD with different TNT concentration solutions

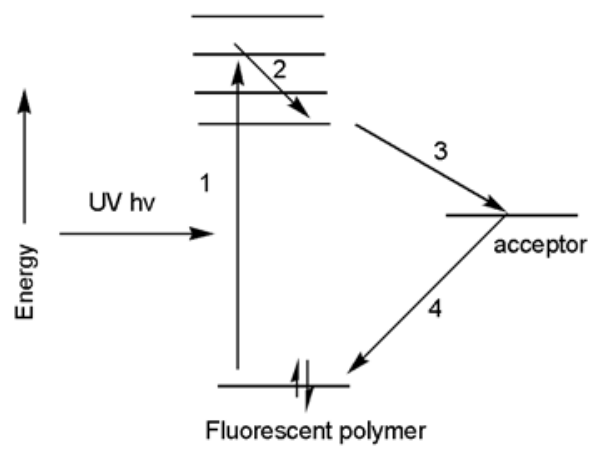

1. UV light excites an electron 2. Non-radiative decay 3. Electron-transfer quenching 4. Back electron-transfer

Figure 13. Electron-transfer fluorescence quenching [32] the energy of the empty $\pi^{*}$ orbitals, thereby making these compounds good electron acceptors. Conjugated polymers are electron donors. Donor ability is further enhanced in their delocalized $\pi^{*}$ excited states. Excited state delocalization is important because exciton migration increases the frequency of interaction with a bound quencher, which contributes to enhanced detection sensitivity. Fluorescent conjugated polymers have therefore been applied to the detection of nitroaromatic explosives. As it can be seen from Figure 12, when the concentration of TNT was only $5 \mathrm{ppm}$, the fluorescence quenching rate of PPV-BD was $10.66 \%$. When the concentration of TNT was $50 \mathrm{ppm}$, and the fluorescence quenching rate of PPV-BD was $37.77 \%$. When the concentration of TNT was $4000 \mathrm{ppm}$, the fluorescence quenching rate of PPV-BD was nearly $100 \%$. Thus, it can be concluded that the polymer PPV-BD may also be suitable for using as a TNT chemosensor material. In short, whether conjugated polymer PPV-BD blending with $\mathrm{C}_{60}$ or TNT, fluorescence quenching is often achieved through an electron-transfer donoracceptor mechanism, as depicted in Figure 13.

\subsection{Electrochemical properties}

Thin film of polymer was drop cast from chloroform $(10 \mathrm{mg} / \mathrm{mL})$. The CV of PPV-BD was carried out in acetonitrile at a potential scan rate of $50 \mathrm{mV} / \mathrm{s}$. Saturated calomel electrode (SCE) served as the reference electrode. It was calibrated with ferrocene $\left(\mathrm{E}_{\mathrm{Fc} / \mathrm{Fc}^{+}}=0.5 \mathrm{~V}\right.$ vs. $\left.\mathrm{SCE}\right)$. HOMO and LUMO energy levels were estimated here on the basis of the reference energy level of ferrocene (4.4 $\mathrm{eV}$ below the vacuum) [33] according the Equation (3):

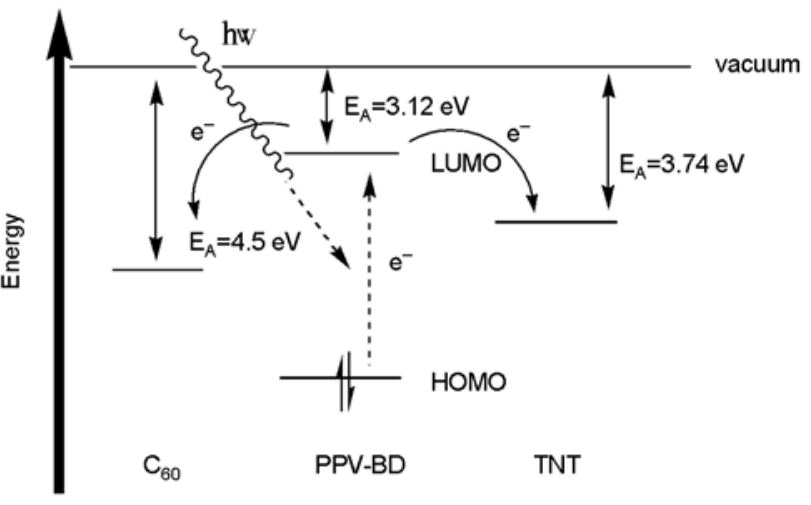




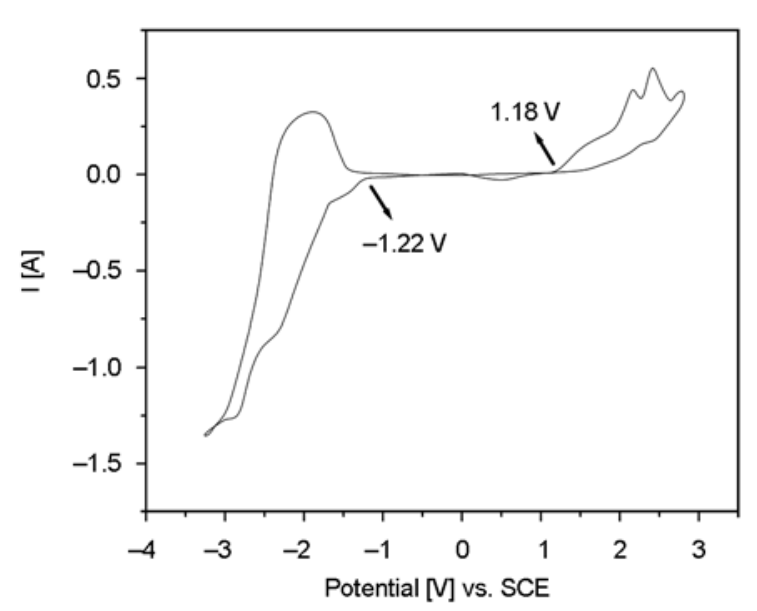

Figure 14. Cylic voltammograms of PPV-BD

$E^{\mathrm{HOMO} / \mathrm{LUMO}}=$

$\left[-\left(E_{\text {onset(vs.SCE })}-E_{\text {onset(Fc/Fc }}{ }^{+}\right.\right.$vs.SCE $\left.\left.)\right)\right]-4.4 \mathrm{eV}$

Figure 14 shows the cyclic voltammograms (CV) of polymer PPV-BD. It shows that polymer PPV-BD reduction and oxidation are irreversible. The oxidations was observed with an onset potential at about $1.18 \mathrm{~V}$ versus SCE and the reductions was observed with an onset potential at about $-1.22 \mathrm{~V}$ versus SCE. The HOMO and LUMO energy levels were estimated to be -5.08 and $-2.68 \mathrm{eV}$. There is an obvious difference between LUMO of polymer PPV-BD and $\mathrm{C}_{60}(-4.5 \mathrm{eV})$ or TNT $(-3.74 \mathrm{eV})$ which makes an effective charge transfer possible between polymer PPV-BD and $\mathrm{C}_{60}$ or TNT. The CV band-gap of polymer PPV-BD is $2.40 \mathrm{eV}$ is slightly larger than its optical band. The discrepancy of values lies within the range of errors, and this discrepancy is probably due to interface barrier for charge injection $[34,35]$.

\section{Conclusions}

A new conjugated polymer with donor-accepter architectures based on alternating 1,4-divinyl-2,5dioctyloxybenzene and 5,8-(2,3-dipyridyl)-quinoxaline was synthesized successfully. The polymer is thermostable, and it has common film-forming ability. The band-gap of PPV-BD was estimated to $1.98 \mathrm{eV}\left(E_{\mathrm{g}}{ }^{\mathrm{opt}}\right)$, which exhibited a reduction compared to MEH-PPV. Similarly, it showed a red-shifted $\mathrm{UV}$-vis absorption peak in comparison to $\mathrm{MEH}-$ PPV. The results show that introduction of quinoxaline units leads to a reduction of the band-gap of poly(p-phenylenevinylenes) (PPVs) copolymers.
Its PCT applications in PSCs and TNT detection were studied respectively, and the results indicated that this polymer might be a good candidate material for PSCs or detecting TNT in solution.

\section{Acknowledgements}

Financial supported by the 'Doctorate Foundation of Northwestern Polytechnical University (Grant No.: CX201118), National Program on Key Basic Research Project (973 Program) (Grant No.: 2010CB635111)' is acknowledged.

\section{References}

[1] Burroughes J. H., Bradley D. D. C., Brown A. R., Marks R. N., Mackay K., Friend R. H., Burns P. L., Holmes A. B.: Light-emitting diodes based on conjugated polymers. Nature, 347, 539-541 (1990). DOI: $10.1038 / 347539 \mathrm{a} 0$

[2] Gross M., Müller D., Nothofer H-G., Scherf U., Neher D., Bräuchle C., Meerholz K.: Improving the performance of doped $\pi$-conjugated polymers for use in organic light-emitting diodes. Nature, 405, 661-665 (2000). DOI: $10.1038 / 35015037$

[3] Müller C., Falcou A., Reckefuss N., Rojahn M., Wiederhirn V., Rudati P., Frohne H., Nuyken O., Becker H., Meerholz K.: Multi-colour organic light-emitting displays by solution processing. Nature, 421, 829-833 (2003).

DOI: $10.1038 /$ nature 01390

[4] Sirringhaus H., Tessler N., Friend R. H.: Integrated optoelectronic devices based on conjugated polymers. Science, 280, 1741-1744 (1998). DOI: $10.1126 /$ science.280.5370.1741

[5] Coakley K. M., McGehee M. D.: Conjugated polymer photovoltaic cells. Chemistry of Materials, 16, 45334542 (2004).

DOI: $10.1021 / \mathrm{cm} 049654 \mathrm{n}$

[6] Chen L., McBranch D. W., Wang H-L., Helgeson R., Wudl F., Whitten D. G.: Highly sensitive biological and chemical sensors based on reversible fluorescence quenching in a conjugated polymer. Proceedings of the National Academy of Sciences, 96, 12287-12292 (1999). DOI: $10.1073 /$ pnas.96.22.12287

[7] Yu G., Wang J., McElvain J., Heeger A.: Large-area, full-color image sensors made with semiconducting polymers. Advanced Materials, 10, 1431-1434 (1998). DOI: 10.1002/(SICI)1521-4095(199812)10:17<1431:: AID-ADMA1431>3.0.CO;2-4

[8] Chochos C. L., Choulis S. A.: How the structural deviations on the backbone of conjugated polymers influence their optoelectronic properties and photovoltaic performance. Progress in Polymer Science, 36, 13261414 (2011).

DOI: $10.1016 / \mathrm{j}$. progpolymsci.2011.04.003 
[9] Kietzke T., Hörhold H-H., Neher D.: Efficient polymer solar cells based on M3EH-PPV. Chemistry of Materials, 17, 6532-6537 (2005).

DOI: $10.1021 / \mathrm{cm} 050148 \mathrm{n}$

[10] Wang Z., Qu S., Zeng X., Liu J., Zhang C., Shi M., Tan F., Wang Z.: The synthesis of MDMO-PPV capped $\mathrm{PbS}$ nanorods and their application in solar cells. Current Applied Physics, 9, 1175-1179 (2009).

DOI: $10.1016 /$ j.cap.2009.01.008

[11] Kim S. C., Naidu B. V. K., Lee S-K., Shin W-S., Jin SH., Jung S-J., Cho Y-R., Shim J-M., Lee J. K., Lee J. W., Kim J. H., Gal Y-S.: Synthesis and photovoltaic properties of novel PPV-derivatives tethered with spirobifluorene unit for polymer solar cells. Solar Energy Materials and Solar Cells, 91, 460-466 (2007).

DOI: 10.1016/j.solmat.2006.10.014

[12] Shen P., Ding T., Huang H., Zhao B., Tan S.: Poly(pphenylenevinylene) derivatives with conjugated thiophene side chains: Synthesis, photophysics and photovoltaics. Synthetic Metals, 160, 1291-1298 (2010). DOI: 10.1016/j.synthmet.2010.03.024

[13] Zou Y., Hou J., Yang C., Li Y.: A novel n-type conjugated polymer DOCN-PPV: Synthesis, optical, and electrochemical properties. Macromolecules, 39, 88898891 (2006).

DOI: $10.1021 / \mathrm{ma} 0626057$

[14] Yu G., Gao J., Hummelen J. C., Wudl F., Heeger A. J.: Polymer photovoltaic cells: Enhanced efficiencies via a network of internal donor-acceptor heterojunctions. Science, 270, 1789-1791 (1995).

DOI: $10.1126 /$ science. 270.5243 .1789

[15] Shaheen S. E., Brabec C. J., Sariciftci N. S., Padinger F., Fromhertz T., Hummelen J. C.: 2.5\% efficient organic plastic solar cells. Applied Physics Letters, 78, 841843 (2001).

DOI: $10.1063 / 1.1345834$

[16] Roncali J.: Synthetic principles for bandgap control in linear $\pi$-conjugated systems. Chemical Reviews, 97, 173-206 (1997).

DOI: $10.1021 / \mathrm{cr} 950257 \mathrm{t}$

[17] Cui Y., Zhang X., Jenekhe S. A.: Thiophene-linked polyphenylquinoxaline: A new electron transport conjugated polymer for electroluminescent devices. Macromolecules, 32, 3824-3828 (1999).

DOI: $10.1021 / \mathrm{ma} 9901994$

[18] Agrawal A. K., Jenekhe S. A.: Electrochemical properties and electronic structures of conjugated polyquinolines and polyanthrazolines. Chemistry of Materials, 8 , 579-589 (1996)

DOI: $10.1021 / \mathrm{cm} 9504753$

[19] Zhang Q. T., Tour J. M.: Alternating donor/acceptor repeat units in polythiophenes. Intramolecular charge transfer for reducing band gaps in fully substituted conjugated polymers. Journal of the American Chemical Society, 120, 5355-5362 (1998).

DOI: $10.1021 / \mathrm{ja} 972373 \mathrm{e}$
[20] Zhang Q. T., Tour J. M.: Low optical bandgap polythiophenes by an alternating donor/acceptor repeat unit strategy. Journal of the American Chemical Society, 119, 5065-5066 (1997).

DOI: $10.1021 /$ ja9640399

[21] Anferov V. P., Mozjoukhine G. V., Fisher R.: Pulsed spectrometer for nuclear quadrupole resonance for remote detection of nitrogen in explosives. Review of Scientific Instruments, 71, 1656-1659 (2000).

DOI: $10.1063 / 1.1150514$

[22] Toal S. J., Trogler W. C.: Polymer sensors for nitroaromatic explosives detection. Journal of Materials Chemistry, 16, 2871-2883 (2006).

DOI: $10.1039 / \mathrm{B} 517953 \mathrm{~J}$

[23] Wang D., Gaylord B. S., Bazan G. C.: Fluorescein provides a resonance gate for FRET from conjugated polymers to DNA intercalated dyes. Journal of the American Chemical Society, 126, 5446-5451 (2004). DOI: $10.1021 / \mathrm{ja} 035550 \mathrm{~m}$

[24] Ashraf R. S., Hoppe H., Shahid M., Gobsch G., Sensfuss S., Klemm E.: Synthesis and properties of fluorene-based polyheteroarylenes for photovoltaic devices. Journal of Polymer Science Part A: Polymer Chemistry, 44, 6952-6961 (2006).

DOI: $10.1002 /$ pola.21645

[25] Thompson B. C., Kim Y-G., Reynolds J. R.: Spectral broadening in MEH-PPV:PCBM-based photovoltaic devices via blending with a narrow band gap cyanovinylene-dioxythiophene polymer. Macromolecules, 38, 5359-5362 (2005). DOI: $10.1021 / \mathrm{ma} 0505934$

[26] Lu S.: Design, synthesis and performance of organic and polymeric photovoltaic materials (in Chinese). Zhejiang University, Hangzhou (2004).

[27] McKean D. D., Parrinello G., Renaldo A. F., Stille J. K.: Synthesis of functionalized styrenes via palladiumcatalyzed coupling of aryl bromides with vinyl tin reagents. The Journal of Organic Chemistry, 52, 422424 (1987). DOI: $10.1021 / \mathrm{jo00379a020}$

[28] Ashraf P. R. S.: Band gap engineering of donor-acceptor $\pi$-conjugated poly(heteroarylene)s and poly(heteroaryleneethynylene)s. Dr. rer. nat. thesis, Friedrich Schiller University of Jena (2005).

[29] Colladet K., Fourier S., Cleij T. J., Lutsen L., Gelan J., Vanderzande D.: Low band gap donor-acceptor conjugated polymers toward organic solar cells applications. Macromolecules, 40, 65-72 (2007).

DOI: $10.1021 / \mathrm{ma} 061760 \mathrm{i}$

[30] Apperloo J. J., Janssen R. A. J., Malenfant P. R. L., Fréchet J. M. J.: Concentration-dependent thermochromism and supramolecular aggregation in solution of triblock copolymers based on lengthy oligothiophene cores and poly(benzyl ether) dendrons. Macromolecules, 33, 7038-7043 (2000).

DOI: $10.1021 / \mathrm{ma} 000793+$ 
[31] Morikita T., Yamaguchi I., Yamamoto T.: New charge transfer-type $\pi$-conjugated poly(aryleneethynylene) containing benzo[2,1,3]thiadiazole as the electronaccepting unit. Advanced Materials, 13, 1862-1864 (2001).

DOI: $10.1002 / 1521-4095(200112) 13: 24<1862:: A I D-$ ADMA1862>3.0.CO;2-\#

[32] Wu C., Peng H., Jiang Y., McNeill J.: Energy transfer mediated fluorescence from blended conjugated polymer nanoparticles. The Journal of Physical Chemistry B, 110, 14148-14154 (2006).

DOI: $10.1021 / \mathrm{jp} 0618126$

[33] de Leeuw D. M., Simenon M. M. J., Brown A. R., Einerhand R. E. F.: Stability of n-type doped conducting polymers and consequences for polymeric microelectronic devices. Synthetic Metals, 87, 53-59 (1997).

DOI: $10.1016 / \mathrm{S} 0379-6779(97) 80097-5$
[34] Chen Z-K., Huang W., Wang L-H., Kang E-T., Chen B. J., Lee C. S., Lee S. T.: A family of electroluminescent silyl-substituted poly( $p$-phenylenevinylene)s: Synthesis, characterization, and structure-property relationships. Macromolecules, 33, 9015-9025 (2000). DOI: $10.1021 / \mathrm{ma} 0005670$

[35] Janietz S., Bradley D. D. C., Grell M., Giebeler C., Inbasekaran M., Woo E. P.: Electrochemical determination of the ionization potential and electron affinity of poly(9,9-dioctylfluorene). Applied Physics Letters, 73, 2453-2455 (1998).

DOI: $10.1063 / 1.122479$ 